\title{
Crafting Identity in League of Legends - Purchases as a Tool to Achieve Desired Impressions
}

\author{
Bastian Kordyaka \\ University of Siegen \\ Bastian.Kordyaka@uni-siegen.de
}

\author{
Sidney Hribersek \\ University of Siegen \\ Sidney.Hribersek@student.uni-siegen.de
}

\begin{abstract}
Within the industry of computer games, one game genre with increasing popularity is Multiplayer Online Battle Arena (MOBA). The diffusion of $M O B A s$ in in the last decade is accompanied by a remarkable economic success and leaping revenues. This development is particularly interesting since MOBAs follow a free-to-play business model in which the majority of purchases consists of virtual items solely of hedonic value. Although research has already identified meaningful explanations in different contexts, an answer to the question what motivates players to purchase virtual items in the context of the most successful MOBA game League of Legends is still scarce. We use the social identity approach and self-presentation theory simultaneously to explain purchases, investigate predictors of self-presentation and explore effects of different self-presentation strategies (self-promotion, ingratiation, exemplification, intimidation, and supplication) on purchases. Results of our survey $(n=209)$ indicate that identification and selfpresentation hold the potential to explain purchases.
\end{abstract}

\section{Introduction}

In the last decade, a heightened significance of virtual markets within the context of computer games occurred opening up novel opportunities for new forms of revenue. One highly relevant market in this domain is eSports, which had a global revenue of $\$ 1.5$ Billion in 2017 [11]. During the last decade, the market experienced a reallocation of revenue from monthly payments in pay-to-play business models to the sale of virtual items in free-to-play business models. Within the context of eSports, the genre of Multiplayer Online Battle Arena (MOBA) games received a heightened attention and is still on the rise of popularity and economic success [27].

MOBAs can be considered a fusion of action games, role-playing games, and real-time strategy games, which makes them a unique configuration of value for players [45]. One particularly noteworthy MOBA game is League of Legends ( $\mathrm{LoL}$ ) which has up to 100 million monthly users and is looked at having the highest revenue within the domian of computer games in 2017 [46].

Surprisingly, a large part of purchases in LoL is comprised of virtual items with only hedonic meaning, which means that players cannot enhance their chances of winning games with the aid of virtual items. Thus, the rather optional character of purchases allows players to play and become the best without having to spend money. Research already proposed symbolic or aesthetic values as motivational drivers explaining purchase behavior [29]. Additionally, a recent meta-analysis revealed that purchases of virtual items follow a servicespecific path [18]. The analysis included services (e.g. Second life, World of Warcraft, Maple Story) that possess different characteristics with much less competition and salience in the digital media compared to LoL. Therefore, the purchase decision of a player in the specific case of LoL is not holistically captured and an open question up to now.

To explain purchases in LoL on a level of theory, we use the social identity approach (SIA) and selfpresentation theory (SPT) simultaneously to better understand purchase behavior. First, looking at research from psychology and consumer behavior, SIA represents a theoretical framework holding the potential to explain purchases. We believe that the SIA is an appropriate approach in the specific context of our study since it allows us to capture salient personal and social shares of the self-concept of a player as well as their interplay at the same point of time. More specifically, we underline the role of identification and the corresponding meaningfulness of the relevant group for the self-concept as a motivational driver of purchases [28, 44]. Second, SPT suggests that the desire to present oneself in a preferred manner to others can motivate the use of objects that fulfill this desire [2]. Extending this line of thought, we presume that, in case of LoL, selfpresentation is a key driver for purchases. Furthermore, we want to test antecedents of self- 
presentation and propose a service specific model explaining purchases in LoL. On a level of practice, we want to derive specific points of reference for game designers and the computer game industry. Therefore, we want to inductively test and better understand effects of different strategies of selfpresentation.

With the paper at hand, we aim to close several existing gaps in Information Systems (IS) and Human-Computer Interaction (HCI) research. First and on the level of theory, a comprehensive framework explaining purchases in the novel context of LoL is missing up to now. Second on a level of practice, there is a lack of understanding what strategies (subscales) of self-presentation have effects on purchase behavior. We take an initial step in both directions by exploring a potential framework and divergent effects of self-presentation strategies.

Against this background, our study is guided by the following research question (RQ):

RQ: What variables explain purchases of virtual items in League of Legends?

\section{Related Work}

\subsection{Social identity approach}

Within the theoretical framework of our study, we understand the self-concept of an individual, which can be also called self-identity, as a collection of beliefs about oneself referring to the characteristics defining an individual's own perception [24]. Individuals seek the attribution of competence, either with reference to general ability or to a specific skill.

Rooted in the SIA (consisting of the social identity theory and the self-categorization theory), identity can be divided into a personal and a social identity [30]. Personal identity refers to the individual and identifies them as different from others. In contrast, social identity identifies the individual as a member of a group and different from other groups. In general, individuals strive for a positive selfconcept, therefore they use social comparisons on the level of individuals and groups aiming for maintaining or enhancing a positive self-concept [22]. Within self-categorization theory, the dynamic salience and context-specific meaningfulness of a group membership for an individual is a function of the perceived identification with the relevant group, which influences behavior [16].

From the perspective of HCI and IS, a corresponding construct that already caught the interest of researchers is online identity $[14,18]$. Kim et al. [19] defined online identity as a configuration of the defining characteristics of a person in an online space. One noteworthy feature in contrast to the offline world is that it is much easier to portray a desired identity in an online context since characteristics can be selectively changed or hidden. A higher level of control over the self-presentation can be identified. In addition, and through the lens of the SIA, an online identity is not necessarily tied to an offline identity and can be quite divergent.

\subsection{Self-presentation theory}

Self-presentation theory (SPT) is a process attempting to influence the perceptions of other people about oneself to present a desired image [10]. Individuals do so by regulating and controlling information selectively in social interactions. SPT distinguishes two different main motives for selfpresentation. First, people aim to influence others and match others' expectations and preferences. Second, they want to present an image to portray a personal and/or social identity [4]. In an online scenario, selfpresentation behavior is especially relevant and occurs in the form of presented textual, symbolic, and aural information from an individual [17]. In the specific case of LoL, opportunities to use virtual items as a tool to manage the impression of oneself in a desired way seem highly relevant. Therefore, we expect a positive relationship to purchases.

\begin{tabular}{l|l} 
Strategy & \multicolumn{1}{c}{ Definition } \\
\hline Self-promotion & $\begin{array}{l}\text { Behavior seeking the attribution of } \\
\text { competence, with reference either to } \\
\text { general ability or to a specific skill. } \\
\text { Behavior designed to influence } \\
\text { others concerning the attractiveness } \\
\text { of one's personal qualities. }\end{array}$ \\
Exemplification & $\begin{array}{l}\text { Behavior seeking to project integrity } \\
\text { and moral worthiness. }\end{array}$ \\
Intimidation & $\begin{array}{l}\text { Behavior seeking the attribution to } \\
\text { have the resources to inflict pain and } \\
\text { stress and the inclination to do so. } \\
\text { Behavioral strategies of advertising } \\
\text { one's dependence to solicit help. }\end{array}$
\end{tabular}

Table 1. Strategies of online self-presentation

Within the framework of SPT, research suggests that self-presentation is a multidimensional construct, which can be aggregated to an overall factor score of a global tendency of self-presentation. Thus, individuals have a general tendency either to engage 
in or avoid using self-presentation [6]. Research already identified a taxonomy of five subscales (strategies) of self-presentation [6]. The proposed strategies of self-promotion, ingratiation, exemplification, intimidation, and supplication have already been utilized in marketing and psychology. To the best of our knowledge, no study in IS or HCI research has tried to explore the different strategies of self-presentation. Therefore, we want to test them in an explorative fashion and do not postulate any hypotheses regarding the specific distinct strategies. Table 1 illustrates the definitions of the selfpresentation strategies [6].

\subsection{Antecedents of self-presentation}

Self-presentation within a game occurs in the framework of a (digital) social situation, which can be predicted through personal and social influences.

Regarding personal influences, literature proposes different predictors of self-presentation. First, research already found out that different personality traits can be associated with self-presentation. Specifically, Batrinca et al. [3] showed that the common Big Five traits conscientiousness (positive connection) and emotional stability (negative connection) have significant impacts on selfpresentation and are the easiest to detect. Second, self-monitoring describes how much people strategically monitor their self-presentation (ability to modify self-presentation). It is closely related to a concern for others' reactions as well as a sensitivity to social and cultural influences (sensitivity to expressive behavior) and showed positive relationships to self-presentation $[1,10,39]$. Third, the level of perceived control over self-presentation is another relevant predictor [28]. Accordingly, Kim et al. [19] illustrated that self-efficacy has a positive effect on self-presentation.

Based on Kelman's fundamental work on selfpresentation, three preconditions of self-presentation regarding social influences can be identified. First, social norms have the potential to predict selfpresentation $[19,26]$. Social norms are closely linked to the construct of critical mass, which showed significant effects in related research [13]. Prior studies showed that the meaningfulness of social norms has a positive effect on self-presentation [19]. Second, research already explored a positive connection between self-presentation and the number of friends [20]. Third, identification holds the potential to play a significant role in explaining selfpresentation [19]. Thus, the level of identification is connected with a feeling of the significance for the self-concept belonging to a certain group [8].

\subsection{Purchase of virtual items}

Historically, two perspectives explaining the purchase of virtual items can be identified. First, a consumer and marketing approach can be detected explaining the purchase of virtual items with the aid of advancement in status, keeping up with others, experience new content, customization, and selfexpression [20]. Second, a perspective dealing with technical affordances to explain purchases can be detected [33, 15]. Oh and Ryu [26] looked at the connection between game mechanics and found a sustained purchase demand. Since we use SIA and SPT, we will focus on the consumer approach to better understand purchase behavior in LoL.

Looking for potential drivers of motivation, research already illustrated that virtual items have attributes that are capable of generating emotional or hedonic responses for individuals. Lehdonvirta [20] classified attributes of virtual items into three general categories, which are functional, hedonic, and social. However, a recent meta-analysis illustrated that purchases of virtual items follow a platform-specific path in MOBA games [15]. Against the background of LoL as our context of interest, we focus on the hedonic and social meaning of virtual items.

\section{Context and aims of the study}

The MOBA game LoL - developed and published by Riot Games - is reasonably one of the most popular online games in the world at the moment and its economic potential is enormous [35]. The game follows a free-to-play business model in which players are granted free access to a fully functional game. As a result, the game has the potential to reach a wide variety of gamers. Riots main source of income is the sale of the in-game currency called Riot Points (RP). Players can buy virtual items using RPs, whereby the majority of them possesses no functional value (champion skins, accessories) and can be considered aesthetic items [23].

Compared to purchases in other services, LoL as a context possesses different unique and striking features, which might be able to explain its wide dissemination and economic success [18, 44]. First, the brand reputation and the associated communication strategy of the game stand out. LoL has the largest footprints of any video game on digital platforms and in streaming media communities (e.g. YouTube, Twitch.tv), which strengthens the economic and social meaning of the game. Second, LoL as a game can be characterized by its competitive nature [42]. Thus, we assume that previous attempts explaining purchases fall short 
regarding the unique context of LoL. Building on the aforementioned theoretical background, we propose the following hypotheses (see Table 2 and Figure 1).

\begin{tabular}{c|l}
\hline 1 & $\begin{array}{l}\text { Statement } \\
\text { Online self-presentation has a positive effect on } \\
\text { purchase behavior. }\end{array}$ \\
\hline 2 & $\begin{array}{l}\text { Identification with the virtual group has a positive } \\
\text { effect on purchase behavior. }\end{array}$ \\
\hline $3 a$ & $\begin{array}{l}\text { Extraversion has a positive effect on online self- } \\
\text { presentation. }\end{array}$ \\
\hline $3 b$ & $\begin{array}{l}\text { Conscientiousness has a negative effect on online } \\
\text { self-presentation. }\end{array}$ \\
\hline $3 \mathrm{c}$ & $\begin{array}{l}\text { Emotional stability has a negative effect on online } \\
\text { self-presentation. }\end{array}$ \\
\hline $3 \mathrm{~d}$ & $\begin{array}{l}\text { Ability to modify self-presentation (AMSP) has a } \\
\text { positive effect on online self-presentation. }\end{array}$ \\
\hline 3e & $\begin{array}{l}\text { Sensitivity to expressive behavior (SEBA) to } \\
\text { others has a positive effect on online self- } \\
\text { presentation. }\end{array}$ \\
\hline 4 & $\begin{array}{l}\text { Online presentation self-efficacy has a positive } \\
\text { effect on online self-presentation. }\end{array}$ \\
\hline 5 & $\begin{array}{l}\text { Online self-presentation social norms have a } \\
\text { positive effect on online self-presentation. }\end{array}$ \\
\hline 6 & $\begin{array}{l}\text { The amount of in-game friends has a positive } \\
\text { effect on online self-presentation. }\end{array}$ \\
\hline effect on online self-presentation.
\end{tabular}

Table 2. Hypotheses of the study

\section{Research Methodology}

\subsection{Research model}

We used a cross-sectional survey to test our hypotheses since we wanted to capture a wide array of variables. Figure 1 on the next page illustrates our research model.

\subsection{Data collection and sample attributes}

To acquire a meaningful amount of respondents for our study we utilized several channels. First, we inserted a message containing the survey link on official community boards. Second, we contacted gatekeepers personally and asked them to share our survey link within the communities to which they had access. Third, we used social media platforms (i.e. Facebook and Reddit) to share our survey link.

We collected data from 236 participants supported by an online questionnaire. We had to exclude 27 participants because of missing data, who did not fully complete the questionnaire. Thus, our final sample consisted of 209 participants. The age of the participants ranged from 14 to 38 years and had an average of close to 21 years $(M=20.64, S D=$ $3.62)$. The vast majority of our sample were males (191) compared to females (18). Furthermore, participants stated that the highest academic degree they already finished in their country was high school (129) or bachelor (56). Additionally, most participants played either on the servers of Europe West (125) or North America (56).

\subsection{Measures of variables}

Wherever possible we used already validated scales adapted to the context of our study. Therefore, we applied the technique of back translation to ensure the validity of our adaptions [9]. Here, both authors adapted every item independently. Afterwards, in case of occurring disagreements, authors discussed their adaptions and consulted an independent researcher to specify the most reasonable solution.

\section{Dependent variable}

Purchase behavior. We asked participants about the amount of money they invested in Riot Points in the current season 7 (start 2017). Respondents answered on a scale ranging from 1 ("none") to 18 ("more than 500") and invested $30 \$ / €$ as an average.

\section{Mediating variables}

Online self-presentation. We adapted 25 items comprising the five strategies of self-presentation [6]. All items used a scale ranging from 1 ("never behave this way") to 5 ("often behave this way"). First, we calculated a scale score of online self-presentation (M $=2.08, \mathrm{SD}=.50, \alpha=.84)$. Subsequently, we computed the five strategies of self-presentation.

Self-Promotion. Consisted of five items (e.g. "Let other players know that you are valuable to the team"; $\mathrm{M}=2.40, \mathrm{SD}=.87, \alpha=.84$ ).

Ingratiation. Comprised five items (e.g. "Compliment other players so they will see you as likeable"; $\mathrm{M}=2.54, \mathrm{SD}=.91, \alpha=.77$ ).

Exemplification. Consisted of five items (e.g. "Try to appear like a diligent, dedicated player"; $\mathrm{M}=$ 2.05, $\mathrm{SD}=.77, \alpha=.71)$. 


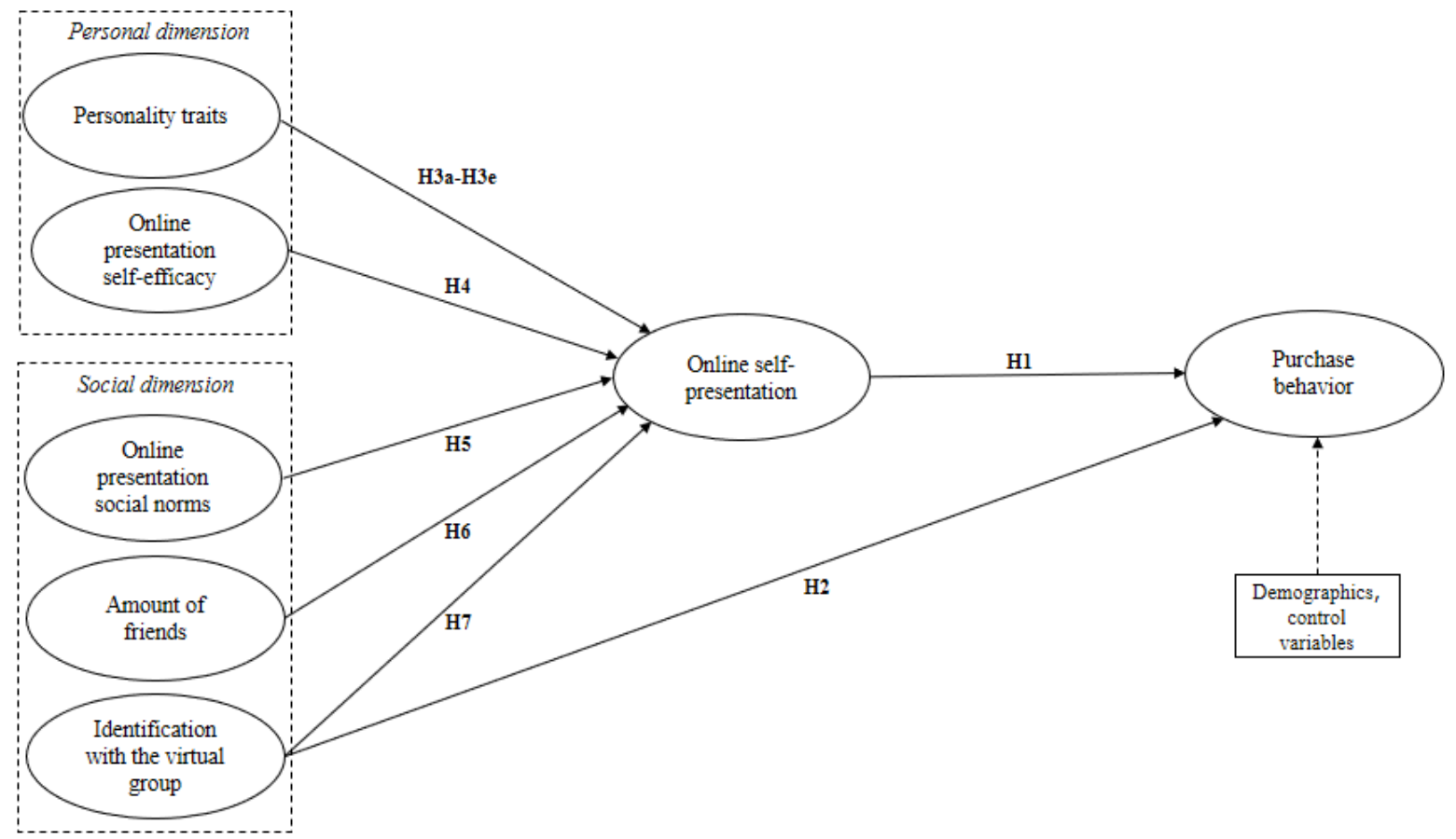

Figure 1: Research model

Intimidation. Consisted of five items (e.g. "Use intimidation to get other players to behave appropriately"; $\mathrm{M}=1.82, \mathrm{SD}=.79, \alpha=.81)$.

Supplication. Comprised five items (e.g. "Act like you need assistance so other players will help you out"; $\mathrm{M}=1.58, \mathrm{SD}=.77, \alpha=.75)$.

\section{Independent variables}

Except the amount of friends all independent variables used a 7-point Likert-scale ranging from 1 ("strongly disagree") to 7 ("strongly agree").

Personality traits - Big Five. Meeting the need for a very brief measure for the Big Five, we used the Ten Item Personality Inventory (TIPI) [11]. The TIPI consists of ten statements representing the traits extraversion (e.g. "extraverted"), agreeableness (e.g. "critical"), conscientiousness (e.g. "self-disciplined"), emotional stability (e.g. "anxious"), and openness (e.g. "conventional") with two items each. The traits of agreeableness $(\mathrm{M}=4.39, \mathrm{SD}=1.16, \alpha=.05)$ and openness $(\mathrm{M}=4.71, \mathrm{SD}=1.25, \alpha=.47)$ showed inadequate reliabilities. Thus, we excluded them for the subsequent analysis. Extraversion $(\mathrm{M}=3.27$, SD $=1.40, \alpha=.63)$, conscientiousness $(\mathrm{M}=4.84, \mathrm{SD}=$ $1.30, \alpha=.60)$, and emotional stability $(\mathrm{M}=5.08, \mathrm{SD}$ $=1.42, \alpha=.72$ ) showed passable values.

Personality traits - Self-monitoring. We adapted the two subscales ability to modify self-presentation (AMSP) consisting of seven items (e.g. "I can regulate my actions appropriately"; $\mathrm{M}=5.05, \mathrm{SD}=$ $.79, \alpha=.66)$ and sensitivity to expressive behavior (SEBA) with six items (e.g. "I understand other players intuitively"; $\mathrm{M}=4.75, \mathrm{SD}=.91, \alpha=.68$ ) to measure self-monitoring $[1,21]$.

Online presentation self-efficacy. We adapted three items (e.g. "I can develop a preferred impression reasonably well in LoL."; $\mathrm{M}=4.89, \mathrm{SD}=$ $1.16, \alpha=.91)$ to measure the construct [32].

Online self-presentation social norms. We adapted three items (e.g. "Many people think it is important to establish a preferred impression in LoL."; $\mathrm{M}=4.05, \mathrm{SD}=1.43, \alpha=.86$ ) to measure online self-presentation social norms [19].

Amount of in-game friends. We asked respondents directly about their amount of in-game friends $(\mathrm{M}=$ 38.47, $\mathrm{SD}=24.83$ ) [20].

Identification with the virtual group. We adapted four items (e.g. "Participating in League of Legends is important to me"; $\mathrm{M}=5.06, \mathrm{SD}=1.03, \alpha=.86$ ) from existing literature [19].

\section{Control variables}

Level of play. We asked participants about their current level of play. Respondents answered the question on an ordinal 7-point scale ranging from 1 ("bronze") to 7 ("challenger"). The vast majority (74\%) played on either on the silver (63), gold (59), or the platinum (32) level. 
Season start. Respondents answered on a 7-point scale ranging from 1 ("Season 1") to 7 ("Season 7"). Most participants started to play in Season 3 (50) and the minority in Season 7 (7). All others ranged between Season 2 (37) and Season 6 (22).

Purchase goal. We asked participants about their predominant purchase goal using RPs regarding three classes of virtual items. Answers showed that, in large parts, players bought champion skins (91\%) compared to champions $(6 \%)$ and accessories $(3 \%)$, which confirmed our underlying postulate that the majority of purchases in LoL (94\%) is comprised of virtual items with only hedonic value.

\section{Results}

\subsection{Upstream Analysis}

Initially, we ran some upstream analysis to test if any of the sociodemographic or control variables had a confounding effect on the dependent variable (purchase behavior) of our study. Therefore, we carried out a multiple regression analysis using the sociodemographic (age, gender, academic degree, server of play) and control variables (level of play, season start, purchase goal) as predictors to explain purchase behavior. The regression equation illustrated a non-significant result $(\mathrm{F}(7,201)=1.54, \mathrm{p}$ $=.16)$ and explained only $2 \%$ of the variance of purchase behavior. To avoid the problem of multiple comparisons, we adjusted our p-values using the false discovery rate. After doing so only the regression weight of purchase goal $(\beta=.21, \mathrm{p}<.05)$ showed a significant effect (all others $\mathrm{p} \geq .84$ ). Thus, we recorded that only the variable purchase goal played a significant role explaining purchases.

\subsection{Hypotheses testing}

To test our hypotheses, we subsequently used two different statistical approaches. First, we apply multiple regression analysis as an initial data-analytic approach. The underlying idea was to reduce the complexity of predictors and capture additional underlying patterns explaining online selfpresentation and purchase behavior. Second, we use the discovered information and apply co-variance based structural equation modelling (path analysis) to conclusively test our hypotheses.

First, we used the independent variables online self-presentation, extraversion, consciousness, emotional stability, AMSP, SEBO, online presentation self-efficacy, online presentation social norms, amount of friends, identification with the virtual group, and the identified confound purchase goal to explain the dependent variable purchase behavior. The multiple regression analysis showed a significant result $(\mathrm{F}(11,197)=4.35, \mathrm{p}<.001)$ and explained $15 \%$ of the variance of the dependent variable. After controlling our p-values using the false discovery rate, the regression weights of purchase goal $(\beta=.18, p<.05)$, online selfpresentation $(\beta=.21, \mathrm{p}<.05)$, and identification with the virtual group $(\beta=.23, \mathrm{p}<.05)$ showed significant effects (all others $\mathrm{p} \geq .31$ ). Thus, we conclude that purchase goal, online self-presentation, and identification with the virtual group played significant roles in directly explaining purchase behavior.

Second, we used another multiple regression analysis inserting extraversion, consciousness, emotional stability, AMSP, SEBO, online presentation self-efficacy, online presentation social norms, amount of friends, and identification with the virtual group as independent variables. The regression equation showed a significant result (F $(9,199)=6.25, p<.001)$ and explained $19 \%$ of online self-presentation. After controlling our pvalues using the false discovery rate, the regression weights of extraversion $(\beta=.20, p<.01)$, emotional stability $(\beta=-.21, p<.01)$, online self-presentation social norms $(\beta=.20, p<.01)$, and identification with the virtual group $(\beta=.26, p<.001)$ showed significant effects. All others did not show a meaningful impact $(\mathrm{p} \geq .10)$. Therefore, we did not find empirical support for our hypotheses $3 \mathrm{~b}$ (consciousness), 3d (AMSP), 3e (SEBA), 4 (online presentation self-efficacy), and 6 (amount of friends) predicting online self-presentation. Thus, we excluded non-significant constructs for the next step.

Third, we used the software AMOS to test the remaining hypotheses using structural equation modelling. The path model (see Figure 2) illustrated a desired non-significant result $(\mathrm{F}(14,209)=13.01, \mathrm{p}=$ .525$, SRMR $=.047, \mathrm{CFI}=.99)$ and good additional fit indices. To answer our remaining hypotheses, we looked at the path coefficients depicted in Figure 2. Both postulated predictors of purchase behavior online self-presentation $(\beta=.24, p<.001)$ and identification with the virtual group $(\beta=.21, \mathrm{p}<$ .001) showed the postulated positive relationships. Thus, we concluded that we found empirical support for hypotheses 1 and 2. Additionally, the tests of the predictors of online self-presentation indicated empirical support for hypotheses $3 \mathrm{a}$ (extraversion, $\beta$ $=.23, \mathrm{p}<.01), 3 \mathrm{c}($ emotional stability, $\beta=-.19, \mathrm{p}<$ .01 ), 5 (online self-presentation norms, $\beta=.21, \mathrm{p}<$ .01 ), and 7 (identification with the virtual group, $\beta=$ $.27, \mathrm{p}<.001)$. 


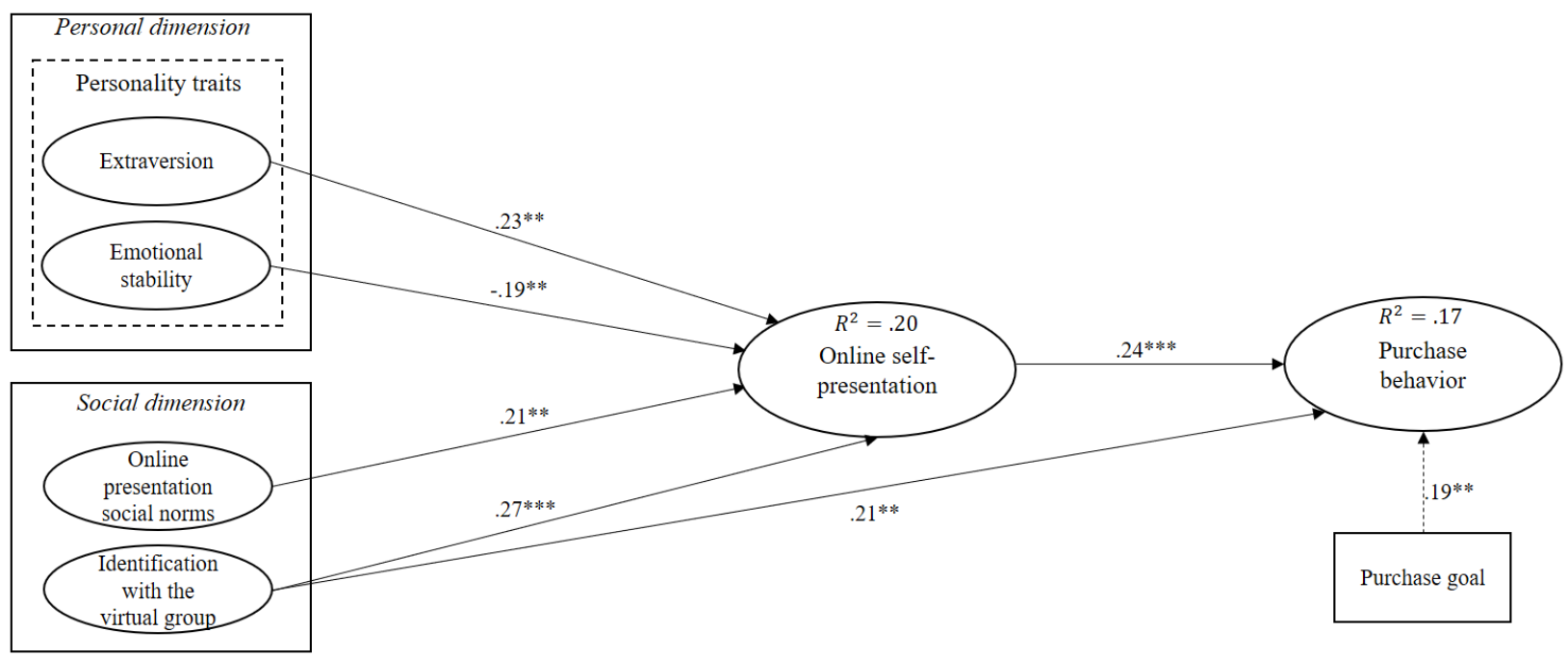

Figure 2: SEM results

\begin{tabular}{|c|c|c|c|}
\hline & DV & IV & Support \\
\hline 1 & Purchase behavior & $\begin{array}{l}\text { Online self- } \\
\text { presentation }\end{array}$ & Yes \\
\hline 2 & Purchase behavior & $\begin{array}{l}\text { Identification with } \\
\text { the virtual group }\end{array}$ & Yes \\
\hline $3 \mathrm{a}$ & Online self-presentation & Extraversion & Yes \\
\hline $3 b$ & Online self-presentation & Conscientiousness & No \\
\hline $3 \mathrm{c}$ & Online self-presentation & $\begin{array}{c}\text { Emotional } \\
\text { stability }\end{array}$ & Yes \\
\hline $3 d$ & Online self-presentation & AMSP & No \\
\hline $3 \mathrm{e}$ & Online self-presentation & SEBA & No \\
\hline 4 & Online self-presentation & $\begin{array}{c}\text { Online } \\
\text { presentation self- } \\
\text { efficacy }\end{array}$ & No \\
\hline 5 & Online self-presentation & Social Norms & Yes \\
\hline 6 & Online self-presentation & Amount of friends & No \\
\hline 7 & Online self-presentation & $\begin{array}{l}\text { Identification with } \\
\text { the virtual group }\end{array}$ & Yes \\
\hline
\end{tabular}

Table 3. Results of the hypotheses testing

\subsection{Additional analysis}

Furthermore, we wanted to explore which of the five strategies of online self-presentation hold the potential to explain purchases of virtual items. Therefore, we used a multiple regression analysis inserting the five strategies of online self-presentation (self-promotion, ingratiation, exemplification, intimidation, and supplication) and the identified covariate purchase goal as predictors explaining the dependent variable purchase behavior. The equation showed a significant result $(\mathrm{F}(6,202)=6.543, \mathrm{p}<$ .001 ) and explained $14 \%$ of the variance of the dependent variable. After controlling our p-values using the false discovery rate, the regression weights of purchase goal $(\beta=.17, \mathrm{p}<.05)$ and exemplification $(\beta$ $=.25, \mathrm{p}<.05$ ) showed significant effects (all others $\mathrm{p} \geq$ .28). Thus, we assumed that only the strategy of exemplification plays a significant role in directly explaining purchase behavior.

\section{Discussion}

\subsection{Argumentation of findings}

In light of our findings, we can address our research question on which variables explain purchases of virtual items in LoL. We found empirical support that self-presentation and identification directly predicted purchase behavior of virtual items. This finding goes in line with the claims that self-presentation can be painted through one's possessions driving their acquisition and that identification decides upon the meaningfulness to demonstrate the desired picture of oneself to others using purchases [19]. Additionally, we expanded empirical knowledge and illustrated that only the self-presentation strategy of exemplification is connected to purchases. All other strategies (selfpromotion, ingratiation, intimidation, and supplication) showed no significant effects. This finding appears to be especially meaningful since it delivers more concrete evidence that revenue can be leveraged by offering desired characteristics of virtual items. 
Furthermore, our study investigated antecedents of self-presentation. On the one hand, we were able to confirm existing findings from prior research. Specifically, the personality traits of extraversion and emotional stability predicted self-presentation. This finding goes in line with results from personal psychology and research on impulsive buying behavior $[2,12]$. Players who are more outgoing, talkative, or energetic and players with more fluid emotions have a bigger drive to present themselves. It is noteworthy that we had to exclude two of the Big Five personality traits included in the TIPI, which can be attributed to the usage of a short scale. Moreover, social norms and identification with the virtual group explained online self-presentation, confirming insights from adjacent research fields in HCI, IS, marketing, and psychology $[5,19]$. Therefore, we understand the positive effect of social norms as the perceived importance of evaluations by other players. Self-presentation in this regard can be understood as an accepted tool to influence others. Moreover, identification was an antecedent of self-presentation unveiling the importance for the self-concept illustrating a desired image of oneself.

On the other hand, we were not able to confirm all our hypotheses. Accordingly, the personality trait of consciousness did not predict online self-presentation. We understand this result as an indicator that the processes connected with self-presentation occur rather implicitly. Furthermore, both dimensions of selfmonitoring (AMSP, SEBA) did not show a significant effect on self-presentation. This finding can be justified by the circumstance that players in LoL rather implicitly use strategic monitoring of themselves, which our explicit measures could not detect [25]. Additionally, self-efficacy was not a meaningful predictor of self-presentation. We understand this reference as an indicator that a sufficient level of selfefficacy is a precondition of the usage of the game. Supplementary, the non-significant effect of the amount of friends might have to do with the circumstance that a majority of the communication between players happens through external game channels like TeamSpeak. Thus, the amount of friends within the game is not a relevant predictor of selfpresentation.

\subsection{Theoretical implications}

First, whereas research already showed that SPT can be a significant predictor of purchase behavior [19], we extended the external validity and showed that self-presentation is a driver for purchases in the realm of LoL as well. Apart from that, our findings oppose and complement existing research in some instances.
As an example, only two (extraversion, emotional stability) of the personal characteristics were meaningful predictors of self-presentation and although we did not hypothesize such relationships we did not find a direct connection to purchase behavior, opposed to findings from other contexts [34]. We understand this result in a bivariate fashion. First, it confirms the meta-analytical finding from Hamari and Keronen that virtual items follow a platform-specific value formation in LoL [15]. Second, we think that it illustrates a more advantaged stage of internalizing the game as part of the self-concept indicated by the more important role of identification. This conclusion can be explained by the remarkably salient trademarks LoL has in the digital media, which might have distilled some effects of the personality traits.

Second, we illustrated that identification is the most meaningful antecedent of self-presentation and has a direct impact on purchase behavior. One possibility to explain this finding is that identification plays a particularly important and central role within the selfconcept of younger people. Taken together, both findings underline the validity of this interpretation. We understand this finding as an extension of the assumptions of Park and Chung to the realm of purchases in LoL [27].

Third, only the strategy of exemplification significantly explained purchases. This finding is particularly noteworthy since it gives a new contentrelated insight regarding the attempts of players associated with the purchase of virtual items. Therefore, our finding can be a starting point to better understand the differential effect of strategies of selfpresentation and form a position for future reference.

\subsection{Practical implications}

First, our results indicate that self-presentation explains purchases of virtual items. Hence, from the perspective of the gaming industry, it is worthwhile to stimulate players' opportunities to present themselves in the game with the aid of virtual items. Thus, a large portfolio of virtual items seems promising. On an explicit level of design, Riot already uses the concept of nudge, which is defined as any aspect of the choice architecture that alters people's behavior in a predictable way without forbidding any options or significantly changing their economic incentives [29]. Accordingly, Riot could use nudges to indicate that positive behavior can be improved by expressing exemplification through virtual items to foster fair play between players and a moral attitude. From a players' perspective, our finding includes a different meaning. Knowing that the portfolio of virtual items is almost infinite and the production costs are marginal, players 
should be aware that there are other and more efficient ways than investing money to exemplify dedicated behavior to other players (e.g. representing friendly behavior and aid using the chat).

Second, our finding that identification with the LoL community is a relevant predictor of self-presentation and purchase behavior offers some opportunities for the gaming industry. With regard to the self-concept of an individual, it is possible to increase the situational salience of identification with the LoL community of a player on a design level [16]. This can lead to higher purchases of virtual items and heightened revenues. Therefore, communication and additional information regarding players could be provided to intensify interaction and consequently identification of players. Therefore, on a level of game design a wider portfolio of communication options (e.g. player profiles going beyond game related statistics or player profile pin boards) could be a path to scale up identification.

\subsection{Limitations and future research}

First, on the level of explanatory power and external validity, it would be useful to further revise the robustness of the contributions of our study attempting to replicate our findings in neighboring contexts. One fruitful way for future research could be to include other MOBA games (such as DotA 2) and explore potential commonalities and differences to better evaluate our findings.

Second, on the level of measurements and the internal validity, we had to deal with a balancing act between the conduct of research in an economic way and preferably detailed measures. Since our study covers a wide array of content, we had to use efficient measurements. One instance where this circumstance became apparent were the internal consistencies of the TIPI. Future studies could use more elaborated scales of personality traits. Furthermore, utilizing scales of self-disclosure and desirability seems to be beneficial complementing self-presentation and avoiding confounding effects in future studies.

Third, on the level of research design, our study includes some issues worth addressing. Since participants of our study self-selected themselves, an undesired effect of selection could have occurred. Future studies can try to explore differences and similarities between different clusters of players, which was not the primary interest of our study. Since we used a survey, we do not have the chance to identify causal connections between the constructs. Using experiments represents a promising avenue for future research. Specifically, future research could try to situationally vary the magnitude of the salience of identification and capture subsequent effects on purchase behavior.

\section{Conclusion}

Since the world of MOBA and the purchase of virtual items has become a major revenue source for the gaming industry, our study takes a quantitative approach to better understand the contemporary picture. Following the call for platform-specific explanations regarding purchase behavior of virtual items [15], our study investigated the main revenue source of the global market leader LoL.

Our study explored the impact of variables that were informed by theory-based empirical studies, and while prior studies mainly focused on behavioral intention, this study examined actual purchase behavior. The data suggests that the mechanisms involved explaining purchases in the specific case of LoL are different from those in other games.

The study identified different variables directly related to spending patterns in LoL. Therefore, selfpresentation and identification play an important role as major drivers for purchases. This finding is particularly interesting since it illustrates the potential to further merge aspects from the SIA and the SPT promising several fruitful avenues for future research.

\section{References}

[1] Bachner-Melman, R., N. Bacon-Shnoor, A.H. Zohar, Y. Elizur, and R.P. Ebstein, "The Psychometric Properties of the Revised Self-Monitoring Scale (RSMS) and the Concern for Appropriateness Scale (CAS) in Hebrew", European Journal of Psychological Assessment 25(1), 2009, pp. 8-15.

[2] Badgaiyan, A.J., and A. Verma, "Intrinsic factors affecting impulsive buying behaviour-Evidence from India”, Journal of Retailing and Consumer Services 21(4), 2014, pp. 537-549.

[3] Batrinca, L.M., N. Mana, B. Lepri, F. Pianesi, and N. Sebe, "Please, tell me about yourself: automatic personality assessment using short self-presentations", Proceedings of the 13th international conference on multimodal interfaces, ACM (2011), pp. 255-262.

[4] Baumeister, R.F., and D.G. Hutton, "Self-Presentation Theory: Self-Construction and Audience Pleasing", In B. Mullen and G.R. Goethals, eds., Theories of Group Behavior. Springer New York, New York, NY, 1987, pp. 71-87.

[5] Blanchard, A.L., and M.L. Markus, "The experienced sense of a virtual community: Characteristics and processes", ACM Sigmis Database 35(1), 2004, pp. 64-79.

[6] Bolino, M.C., and W.H. Turnley, "Measuring impression management in organizations: A scale development based on 
the Jones and Pittman taxonomy", Organizational Research Methods 2(2), 1999, pp. 187-206.

[7] Day, D.V., and D.J. Schleicher, "Self-Monitoring at Work: A Motive-Based Perspective", Journal of Personality 74(3), 2006, pp. 685-714.

[8] van Dick, R., "Identification in organizational contexts: linking theory and research from social and organizational psychology", International Journal of Management Reviews 3(4), 2001, pp. 265-283.

[9] Douglas, S.P., and C.S. Craig, "Collaborative and Iterative Translation: An Alternative Approach to Back Translation", Journal of International Marketing 15(1), 2007, pp. 30-43.

[10] Goffman, E., The Presentation of Self in Everyday Life, Peter Smith Publisher, Incorporated, 1999.

[11] Gosling, S.D., P.J. Rentfrow, and W.B. Swann, "A very brief measure of the Big-Five personality domains", Journal of Research in Personality 37(6), 2003, pp. 504-528.

[12] Guido, G., "Shopping motives, big five factors, and the hedonic/utilitarian shopping value: An integration and factorial study", Innovative Marketing 2(2), 2006, pp. 57-67.

[13] Guo, Y., and S. Barnes, "Why people buy virtual items in virtual worlds with real money", ACM Sigmis Database 38(4), 2007, pp. 69-76.

[14] Haimson, O.L., J.R. Brubaker, L. Dombrowski, and G.R. Hayes, "Digital Footprints and Changing Networks During Online Identity Transitions", ACM Press (2016), pp. 2895-2907.

[15] Hamari, J., and L. Keronen, "Why do people buy virtual goods: A meta-analysis", Computers in Human Behavior 71, 2017, pp. 59-69.

[16] Haslam, S.A., P.J. Oakes, K.J. Reynolds, and J.C. Turner, "Social identity salience and the emergence of stereotype consensus", Personality and Social Psychology Bulletin 25(7), 1999, pp. 809-818.

[17] Jensen Schau, H., and M.C. Gilly, "We are what we post? Self-presentation in personal web space", Journal of Consumer Research 30(3), 2003, pp. 385-404.

[18] Kim, H.-W., and H.C. Chan, "Why people pay for digital items? Presentation desire of online identity", PACIS 2007 Proceedings, 2007, 7.

[19] Kim, H.-W., H.C. Chan, and A. Kankanhalli, "What Motivates People to Purchase Digital Items on Virtual Community Websites? The Desire for Online Self-

Presentation", Information Systems Research 23(4), 2012, pp. $1232-1245$.

[20] Lehdonvirta, V., "Virtual item sales as a revenue model: identifying attributes that drive purchase decisions",

Electronic Commerce Research 9(1-2), 2009, pp. 97-113.
[21] Lennox, R.D., and R.N. Wolfe, "Revision of the selfmonitoring scale.", Journal of Personality and Social Psychology, 46(6), 1984, pp. 1349-1364.

[22] McLean, K.C., and M.U. Syed, The Oxford handbook of identity development, Oxford Library of Psychology, 2014.

[23] Meer, A., "Is free really the future of gaming?", Techrader, viewed on the 4, 2009.

[24] Myers, D., Social Psychology, McGraw-Hill Education, 2012.

[25] Nosek, B.A., "Implicit-explicit relations", Current Directions in Psychological Science 16(2), 2007, pp. 65-69.

[26] Oh, G., and T. Ryu, "Game Design on Item-selling Based Payment Model in Korean Online Games.", DiGRA Conference, 2007.

[27] Park, S., and N. Chung, "Mediating roles of selfpresentation desire in online game community commitment and trust behavior of Massive Multiplayer Online RolePlaying Games", Computers in Human Behavior 27(6), 2011, pp. 2372-2379.

[28] Smith, J.B., and M. Colgate, "Customer Value Creation: A Practical Framework", Journal of Marketing Theory and Practice 15(1), 2007, pp. 7-23.

[29] Sunstein, C., and R. Thaler, "Nudge", The politics of libertarian paternalism. New Haven, 2008.

[30] Tajfel, H., and J.C. Turner, "The Social Identity Theory of Intergroup Behavior.”, 2004.

[31] Tyler, J.M., P.O. Kearns, and M.M. McIntyre, "Effects of Self-Monitoring on Processing of Self-Presentation Information", Social Psychology, 2016.

[32] Venkatesh, V., "Determinants of perceived ease of use: Integrating control, intrinsic motivation, and emotion into the technology acceptance model", Information systems research 11(4), 2000, pp. 342-365.

[33] Wohn, D.Y., "Spending real money: purchasing patterns of virtual goods in an online social game", ACM Press, 2014, pp. 3359-3368.

[34] Yee, N., "The Gamer Motivation Profile: What We Learned from 250,000 Gamers", In Proceedings of the 2016 Annual Symposium on Computer-Human Interaction in Play, ACM Press, 2016, p. 2.

[35] "Report: League of Legends is No. 1 in PC game revenue so far in 2017", Slingshot Esports, 2017. https://slingshotesports.com/2017/08/03/league-legends-toppc-game-revenue-2017/. 